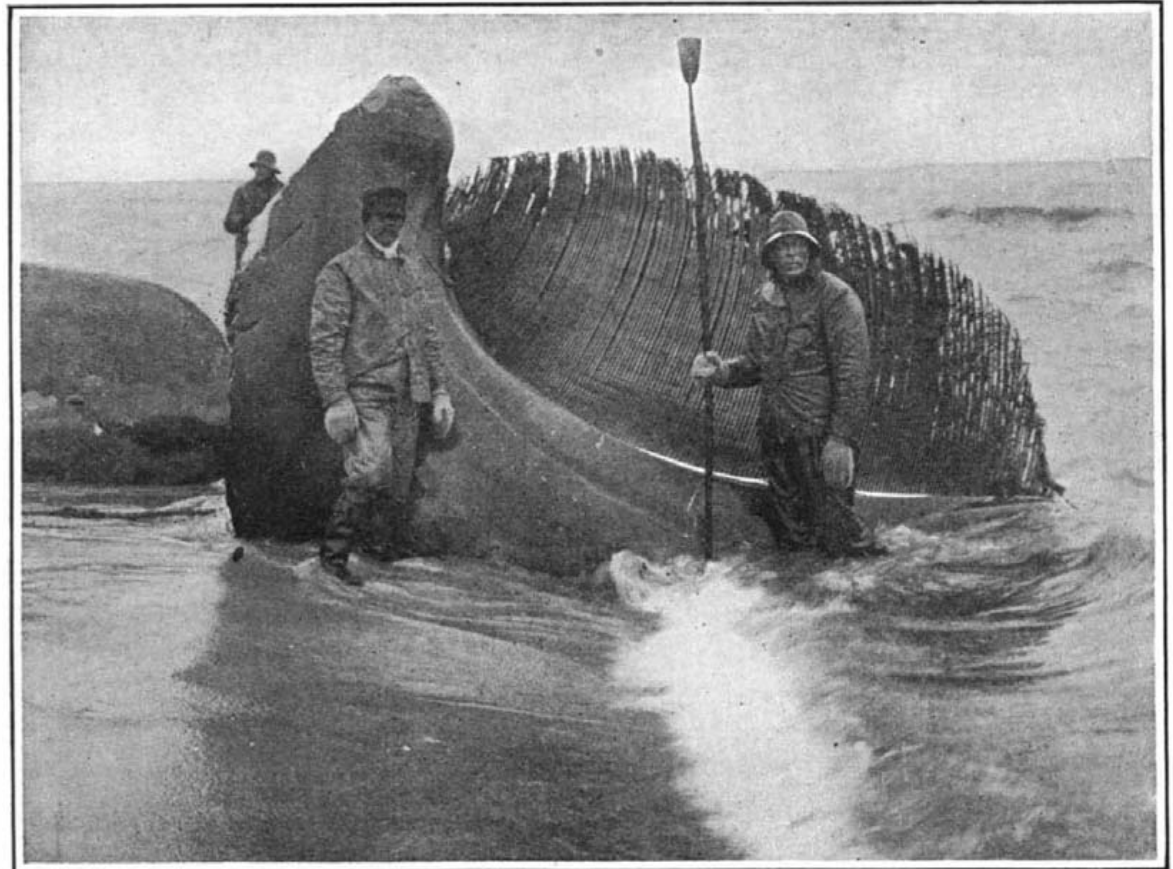

The upper jaw of a whale before any of the whalebone has been removed

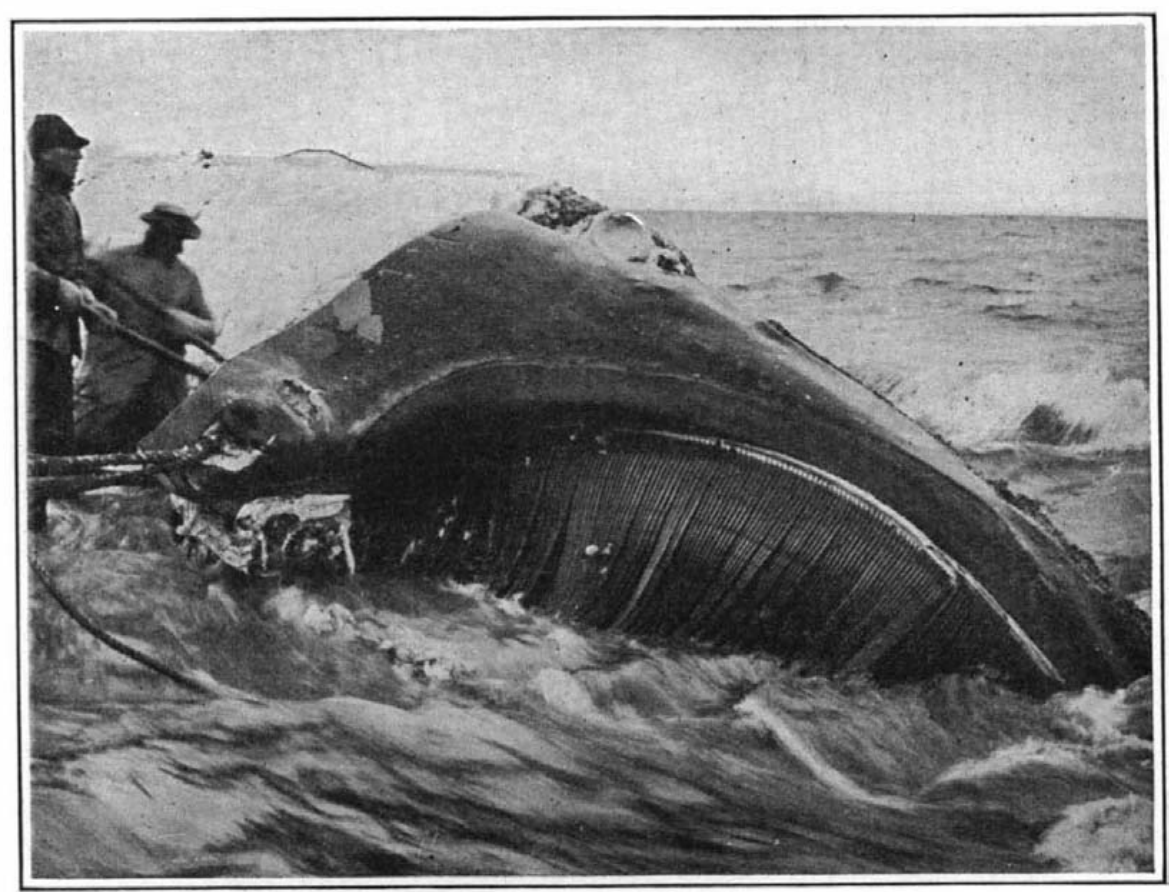

Dragging the partially cut up body of a whale out of the rising sucf

\title{
The Whale as a Food Factor
}

\section{Sea-Grown Meat That Compares Favorably With Beef \\ By C. H. Claudy}

Photographs copyrighted by Underwood \& Underwood

Whale Croquettes. -3 cups left-over cold roast whale finely chopped; $11 / 2$ teaspoonfuls salt, trifle pepper 3 tablespoonfuls melted butter; $1 / 2$ teaspoonful savory (optional); 2 sprigs parsley, finely chopped; 1 large onion, finely chopped; 6 to 8 walnuts.

Moisten with just sufflcient gravy

to hold meat together. Shape into croquettes. Egg and crumb in the same manner as the cutlets, and fry in deep fat for about 8 minutes. The fat should be sufficiently hot to brown a piece of white bread in 45 seconds. and sweet pickles.

Nore.-The same mixture may be moistened with a beaten egg, formed made into Whale Hash, and served on points of toast.

THE above is not a joke! It is one of 1 several tried and proven recipes for using whale meat. Yes "meat"-not "fish." The whale is a red-blooded, warm-blooded, sea-inhabiting animal, not a fish.

Until very recently the whale was of commercial value only for the oil from its blubber, and the fertilizer which could be made of its flesh, viscera and bones. Today whales are not only killed for their fat and oil, but are proving of economic

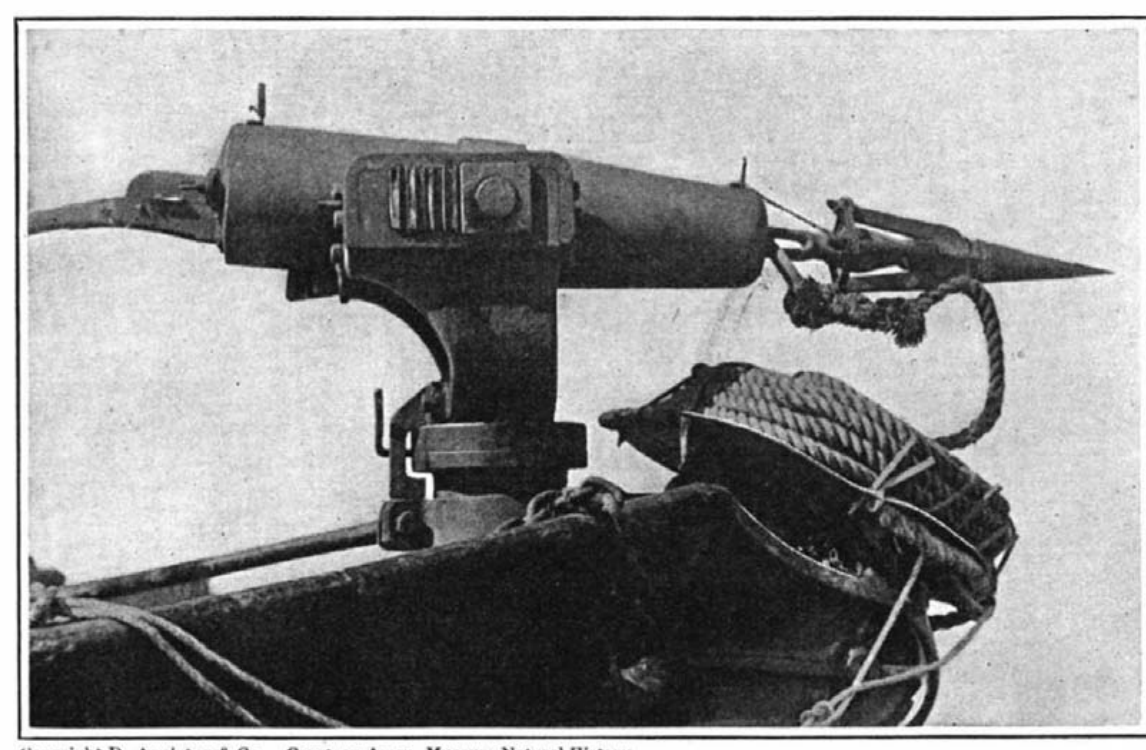

Whale-gun and harpoon set for action eight tons of flesh for food for human beings. This action of which is somewhat similar to castor oil. So the
is equivalent to the flesh, in quantity at least which bottle-nosed whale is no source of food! The other is equivalent to the flesh, in quantity at least which bottle-nosed whale is no source of food! The other would be obtained from a herd of about 25,000 cattle - whales, however, yield flesh which tastes so much like thing save the fact that whale meat is cor in fiber and darker in color than coarser in fiber and darker in color than accompanied by toughness-whale meat, properly prepared, is as tender as good beef, and when put on the table without a label is usually mistaken for beef, or, sometimes young pig.

The public associates blubber and oil with the idea of whale. The association is natural, but unjust to the food. What is eaten is the muscular fiber of the whale, which is found beneath the heavy oily skin and the blanket of blubber or fat which is "tried out" for its oil This muscular fiber is not solid, but contains a sufficient amount of fat to make it a well balanced meat ration and this intramuscular fat is of a fine white flaky texture, without any of the oiliness which distinguishes the blubber.

So far, comparatively little whale meat has found its way eastward, although it has appeared from time to time in some New York hotels, where it has been more value as food and by no means as an experiment. Sug- supply is so much below the demand. The flesh of of a curiosity than a regularstaple of diet. In cans, howgested as a food by the Bureau of Fisheries in May, 1917, almost all the whales, with the exception of the bottlelast year nearly a. thousand whales were killed near the nosed whale, is not only edible but enjoyable. The Pacific coast and made to yield not only their normal bottle nosed whale has an oily taste to his flesh, and product of oil and fertilizer but an average of nearly worse, this oil taste comes from an oil in the flesh the

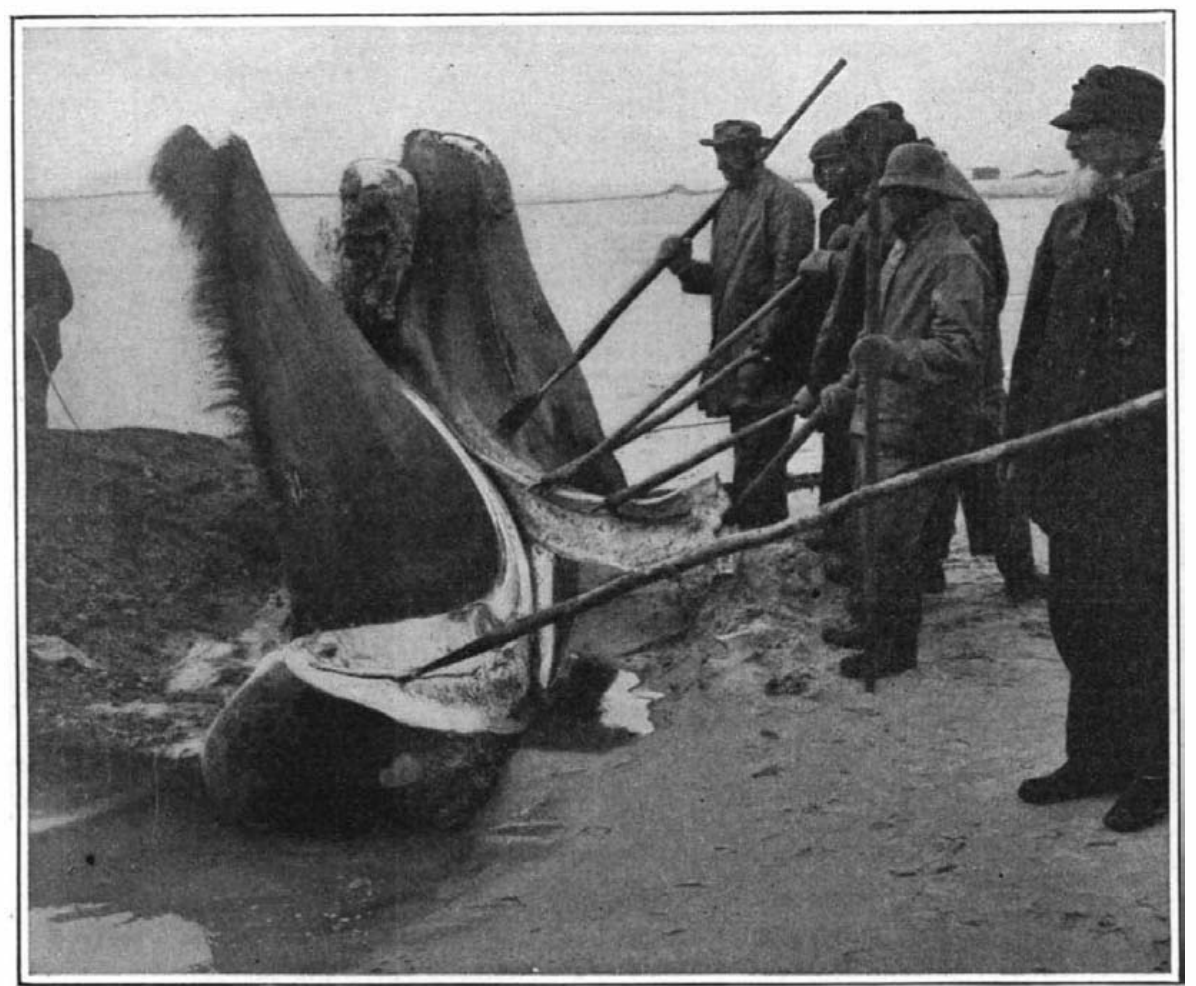

Performing a major operation on the jaw of a whale

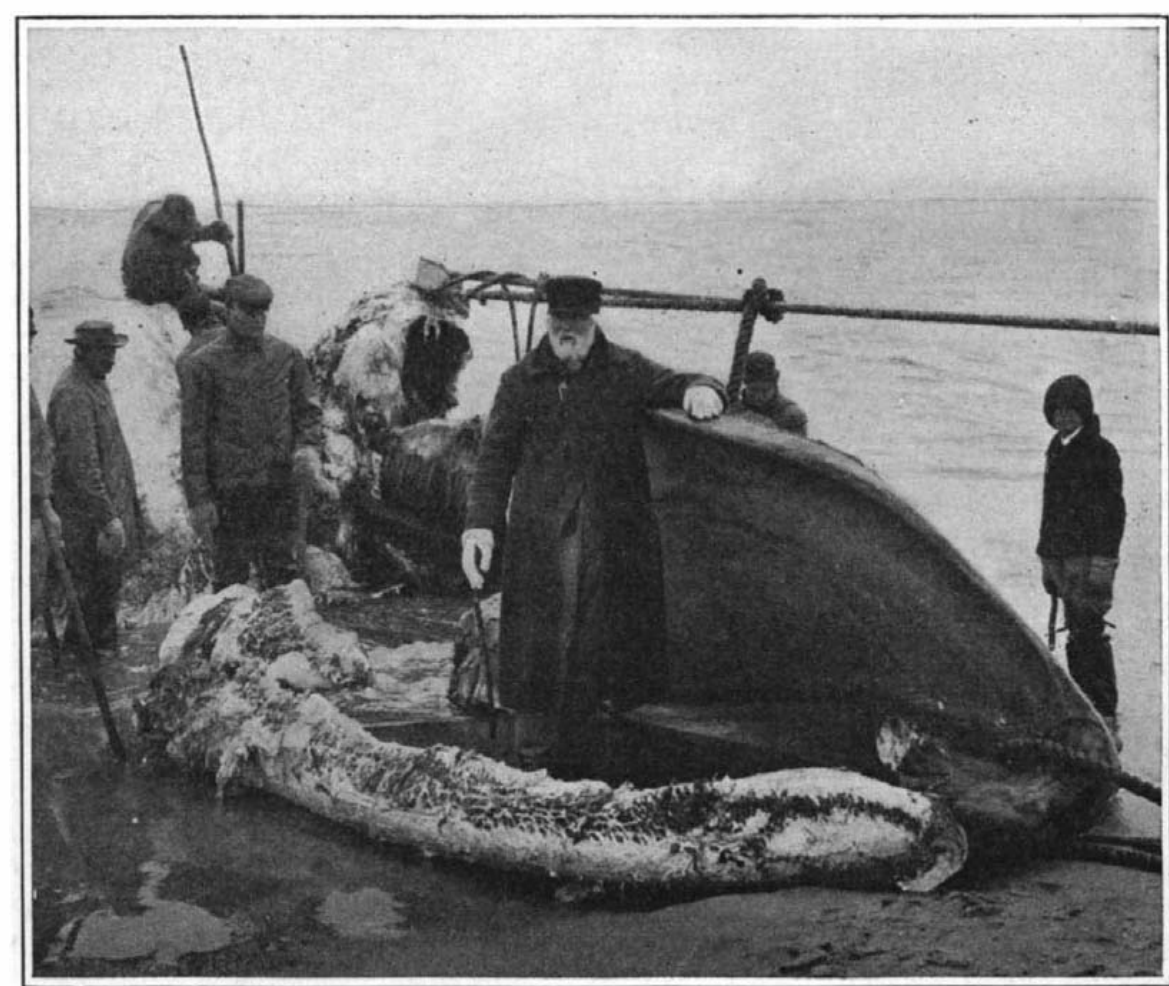

Dismantled carcass of a whale caught on the Long Island coast 
The supply is on the increase. The shore whaleries of the Pacific Coast were not prepared to realize on the meat as meat when the demand was made upon them. After trying out the blubber for oil, the rest of the carcass was turned into fertilizer at perhaps two cents a pound. Whale meat at ten cents a pound represented so tempting a buy to the housekeeper and so unexpected a profit to the whale killer, that the demand has been met as fast as the necessary plants could be erected. The price has been as high as 221/2 cents a pound in San Francisco which, though perhaps high, is cheaper than beef, particularly when it is considered that there is little if any waste in whale meat. When a whale is towed to shore, now, the blubber is removed to get at the meat, and that is "harvested" first, either for direct shipment to market, or for putting into the recently erected cold storage plants, or for the cannery.

It seems not unlikely that the meat, hitherto a by-product, will shortly become the principal yield of the whaling industry with blubber and oil the by-product, although the skin and parts of the viscera are showing astonishing possibilities, of which more in a moment. A forty or fifty-ton whale will yield from ten to fifteen tons of meat and from six to eight tons is an average yield from the average whale. Inasmuch as the meat is all together and not scattered among many carcasses, as with beef, and as the killing takes place in the ocean, and there are no expenses of slaughter houses, railroad transportation and similar factors in ordinary packing, the price of whale meat should always remain considerably below that of good beef.

By no means all the meat of one whale is of one grade, nor are all whales similar in the yield of meat as to tenderness. The matter is as yet too new to have arrived at any very accurate knowledge of the most tender cut of whale, or of the best kind of whale from which to get a steak or roast. Incidentally, if there is no known means of feeding whale stock to produce "fancy beef" neither is there any expense on "pasturing" whales which will probably continue to feed themselves and be available as food as long as the supply lasts.

Undoubtedly this time is limited-perhaps not by any definite number of years, but as unquestioned by authority as the (all but) extinction of the buffalo and the practical extinction of the right whale and bow-whale today. Should international laws be enacted looking to the conservation of this economic asset, the threatened extinction may be averted, but whether or not the pressing political questions growing out of the great conflict will leave time for whale fishing regulatory laws seems problematical.

However, the whale will supply good food in rapidly increasing quantities while he lasts. Perhaps almost equally important is the fact that the whale's skin, his stomach and his intestines have developed an entirely new source of a high grade of leather.

Before the shortage of leather made any possible source a matter of serious import, whale skin was considered too oily to tan. Now, it has been discovered that by putting the skin through a wringer and squeezing out the free oil, the skin can be tanned to a thick, tough leather of fine grain and with the peculiar quality of stretching sidewise but not lengthwise. The skin of a whale, which frequently shows folds on the belly, is loose in a lateral direction either to accommodate his body to variations of pressure or to expand as he swells with a hearty meal. This quality remains in the finished leather. Whether it will be an asset or not depends on the uses to which whale leather is put.

There seems to be no doubt that the yield of 3,000 square feet of good leather will add considerably to a whale's value, however, and this is without taking into account the fact that his intestines yield 300 square feet of a fine white leather closely approaching kid in texture, and of a toughness much greater than kid. The stomach yields a similar leather of even greater toughness-so strong that a strong man cannot tear it by trying to pull it apart, whereas a kid skin is easily torn by the same exertion.

Altogether, it seems that the whale has been a somewhat neglected source of human wealth and comfort, and that the animal which has previously done little but supply oil, fertilizer, and romance for writers of sea stories, has been, all along, a source of food and leather, the value of whicu far transcends its other wealth.

Bombing and Getting Bombed

THE day of the bombins plane is here. than once we may have considered the prewar writings of many a novelist, picturing frightful air raids with their accompanying

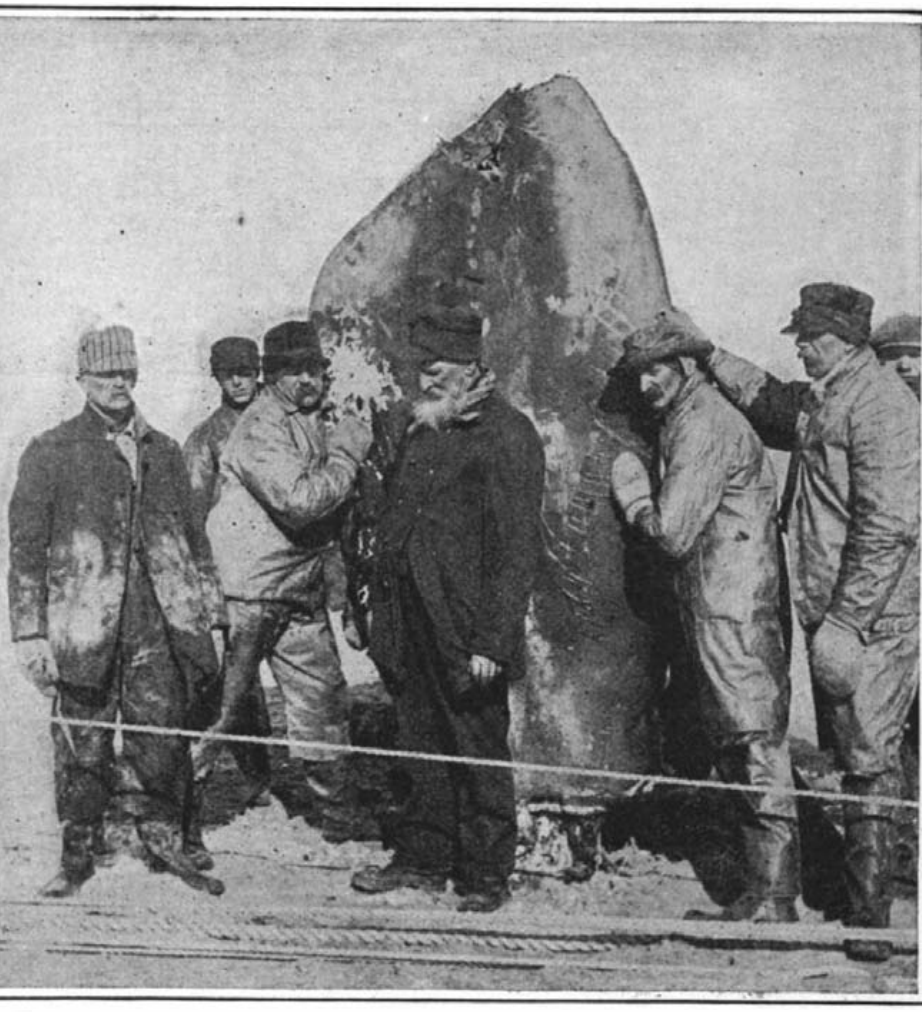

The fin of a whale caught off the Long Island coast. It is nine feet eleven inches long

toll in lives and property, as far-fetched; but every indication points to the extensive employment of the bombing plane this year. Both sides are going to bomb railroads and factories and towns and camps far in the enemy country. This, we are told by men in a position to know, is going to be a war behind the lines, with the

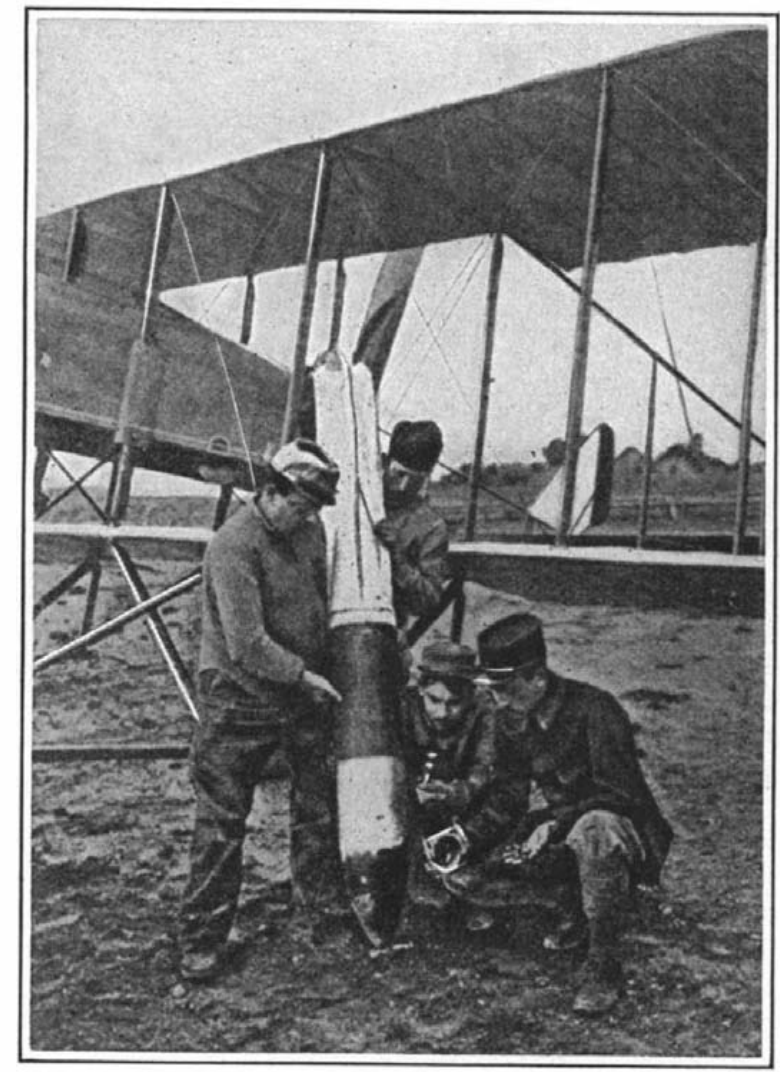

A $220 \mathrm{~mm}$. shell with tail fins for bombing purposes, being prepared for a German target

attackers winging their way high above the intrenched lines and massed guns.

How effective is aerial bombing? That is a question which is difficult to answer. The bombs used early in this war were small and therefore of very limited destructive power. Sighting was still crude. But with

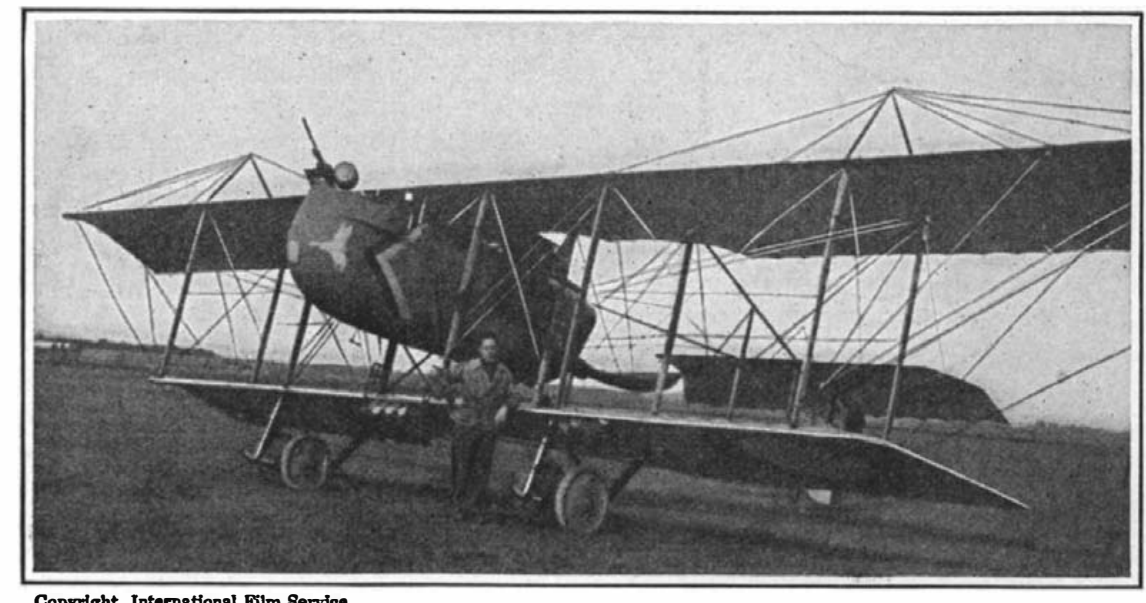

Farman pusher biplane of $\mathbf{1 7 0}$ horsepower. This machine is typical of the French bombing service the present bombs weighing anywhere from 50 to 400 pounds the destructive power of these missiles has been increased many fold. It is said of the latest German bombs that their destructive power is tremendous; for the time being they hold first place. As things go in aeronautics, however, this superiority is temporary. Already our French allies are at work on a bomb far more frightful in its effects.

British and German bombing is generally carried out with large machines. The former are now making use of large Handley-Page biplanes, while the latter are using fleets of Gotha biplanes. Either of these twin-engine types can carry upwards of a dozen large bombs, and are ideal for this class of work. On the other hand the French air service, although capable of building large machines and, indeed, possessing several excellent twin-engined types, for some reason or other prefer to continue using comparatively small Farman pusher biplanes, each capable of carrying several small bombs or one large torpedo.

Germany, that exponent of ruthless warfare and frightfulness, has thus far confined her bombing activities to enemy cities, such as London, Dunkirk, Dover, Nancy and other centers of population in France and England. Hers has been a campaign against civilians, with not a shred of legitimate excuse on the grounds of military necessity. The Entente air fleets, on the other hand, have conducted a vigorous air campaign against German works, camps and railroads, with an occasional raid over a German city as a reprisal for German air attacks on civilians.

Just how effective legitimate air raiding is may be judged by one case. It is said on good authority that certain French bombing squadrons, attacking night after night, weather conditions permitting, have reduced the iron production in the Briey region by at least 50 per cent. The Germans occupying that district are so hampered in their work by the nocturnal raiders that there exists a state of semi-disorganization. The Krupp works on at least one occasion has suffered some loss, but nothing can be learned definitely until after the war-and perhaps not even then. But it is known that numerous German railroads have been hampered by air raids, especially at times when it proved mighty inconvenient to frenzied commanders endeavoring to rush up troops and artillery to some hard pressed section of the line.

It remains for 1918, however, to witness the greatest aerial bombing activities. Both sides are going to send vast fleets into the enemy country. Civilians are going to suffer as never before-if adequate protection is not provided. In the case of the Allied countries it is to be hoped that defensive squadrons will be available in sufficient numbers to discourage the wholesale bombing of positions back of the line. For the side that can ward off enemy bombers while in turn sending its own bombing fleets far into hostile skies, is going to have a telling advantage in the year's campaigns.

The Soap-Nut Tree

MR. E. MOULIE, of San Diego, Cal., the father of I the soap-nut tree (Sapindus Muskorossi), in the United States, will this spring conduct another distribution of the seed of this interesting tree.

In our issue of March 1911 we gave considerable space to setting forth the qualifications of the soap-nut tree. Briefly to restate these, the nut is not only good to eat, but contains an incredible amount of fat and soap-making materials, the former in the kernel, the latter in the shell. We recall that in 1911 we used the nuts furnished us by Mr. Moulié, to wash the editorial hands for a week or so, and then cracked them and ate the kernels with no less relish.

The tree is $\mathbf{5 0}$ feet tall when fully developed, quite ornamental, with timber resembling orangewood. It bears nuts when six years old. The nut value is $\$ 10$ to $\$ 20$ per tree for the average crop of 200 pounds. The nut has valuable medicinal properties, and the leaves are a splendid fodder. The hull contains the detergent principle, saponin. This by itself is a soap equal to any that human skill can devise, according to the claims of $\mathrm{Mr}$. Moulié. On the basis of its oil and its general food value the kernel surpasses in value the peanut. Industrially and commercially the soap-nut forms the raw material for an immense variety of finished products. It costs practically nothing tor the growing and harvesting. Today there are perhaps it million of the trees in the United States, mostly in Florida and California.

Mr. Moulié will fill orders for seed nuts at one cent per ounce to cover postage, plus 5 cents with each order to defray the cost of packing, etc. 